\title{
IMPLEMENTASI ALGORITMA SEAL PADA KEAMANAN DATA
}

\author{
I Made Kartika, Restyandito, Sri Suwarno \\ Fakultas Teknologi Informasi, Program Studi Teknik Informatika \\ Universitas Kristen Duta Wacana Yogyakarta \\ Email: 22043639@students.ukdw.ac.id, ditto@ukdw.ac.id, sswn@ukdw.ac.id
}

\begin{abstract}
Abstrak :
Masalah keamanan dan kerahasiaan merupakan salah satu aspek penting dari suatu pesan, data, atau informasi. Hal ini sangat terkait dengan betapa pentingnya pesan, data, atau informasi tersebut dikirim dan diterima oleh pihak atau orang yang berkepentingan, apakah pesan, data, atau informasi masih authentic. Pesan, data, atau informasi akan tidak berguna lagi apabila di tengah jalan informasi itu disadap atau dibajak oleh orang yang tidak berhak atau berkepentingan. Oleh karena itu dibutuhkan suatu siatem yang dapat membantu dalam menjaga keamanan maupun kerahasiaan suatu data.

Kriptografi merupakan salah satu metode pengamanan data yang dapat digunakan untuk menjaga keamanan maupun kerahasiaan dari suatu data. Dari permasalah ini penulis akan menimplementasikan algoritma kriptografi SEAL dalam menjaga kerahasiaan dan keamanan data dengan melalui proses enkripsi dan deskripsi, sehingga orang yang tidak berhak tidak dapat membaca informasi yang ada didalam data tersebut.
\end{abstract}

Kata Kunci : Kriptografi, Enkripsi, Stream Chiper, SEAL

\section{Pendahuluan}

Arus informasi yang semakin marak untuk menggunakan media digital, dalam bentuk file memungkinkan orang lain untuk bisa membuka data yang bukan haknya. Rahasia perusahaan, data-data penting menjadi sangat berarti untuk dilakukan proses enkripsi. Hal ini sangat membantu bagi pihak-pihak yang berkepentingan dengan data untuk melindungi datanya dari orang pihak-pihak lain..

Pada kenyataannya ada banyak sekali tipe data yang dapat di-enkripsi, salah satu diantaranya adalah data teks. Saat ini sudah ada beberapa algoritma untuk menjaga keamanan data teks, seperti DES, AES (Rijndael), Blowfish, TEA, XOR256 Block, XOR256 Stream dan SEAL. Masing-masing algoritma memiliki kelebihan yang berbeda-beda. Dalam penelitian ini 
penulis akan membahas mengenai algoritma SEAL untuk pengamanan data file teks.

Algoritma Seal merupakan salah satu algoritma kriptografi untuk mengamankan data. Oleh sebab itu, perlu dibangun sebuah sistem untuk mengaplikasikan algoritma SEAL dengan melibatkan proses enkripsi dan dekripsi sehingga dapat dianalisis lebih dalam mengenai struktur chiper dan cara kerja algoritma kriptografi SEAL dengan beberapa pengujian sehingga dapat dilakukan analisa terhadap perubahan hasil keluaran (output) yang terjadi jika terjadi perubahan pada masukan (input) sehingga dapat diketahui seberapa baik proses enkripsi dengan algoritma kriptografi SEAL dalam memproteksi data.

\section{Landasan Teori}

\subsection{Kriptografi}

Secara etimologi (ilmu asal usul kata), kata kriptografi berasal dari gabungan dua kata dalam bahasa Yunani yaitu "kriptos" dan "graphia". Kata kriptos digunakan untuk mendeskripsikan sesuatu yang disembunyikan, rahasia atau misterius. Sedangkan kata graphia berarti tulisan. Kriptografi adalah seni dan ilmu dalam mengamankan pesan. Dalam dunia kriptografi, pesan disebut plaintext atau cleartext. Proses untuk menyamarkan pesan dengan cara sedemikian rupa untuk menyembunyikan isi aslinya disebut enkripsi. Pesan yang telah dienkripsi disebut ciphertext. Proses pengembalian sebuah ciphertext ke plaintext disebut dekripsi.

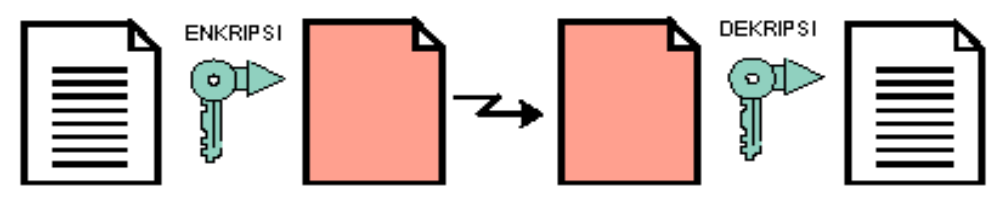

Gambar 1. Konsep Dasar dari Enkripsi dan Dekripsi

\subsection{Stream Chiper}

Stream cipher adalah suatu algoritma simetrik enkripsi yang sangat penting. Algoritma ini bekerja dengan cara mengenkrip karakter demi karakter (biasanya digit binary) dari plaintext. Stream cipher jauh lebih cepat dibandingkan dengan algoritma block cipher. Algoritma ini secara umum digunakan untuk mengenkrip plaintext yang kecil biasanya dalam ukuran bit. Suatu stream cipher menghasilkan apa yang disebut suatu keystream (suatu barisan bit yang digunakan sebagai kunci) untuk menghasilkan pseudo-random sequence yang diinisialisasikan dengan menggunakan kunci rahasia yang kemudian dilakukan operasi XOR dengan plaintext untuk menghasilkan ciphertext. 


\subsection{Algoritma SEAL}

SEAL merupakan singkatan dari "Software Encryption Algorithm", yang merupakan salah satu algoritma enkripsi stream chiper yang dibuat oleh Rogaway dan Coppersmith dan dipatenkan oleh perusahaan IBM pada tahun 1993. SEAL digunakan secara luas pada beberapa aplikasi dan umumnya dinyatakan sangat aman. Sampai saat ini belum diketahui siapa yang dapat memecahkan/membongkarnya.

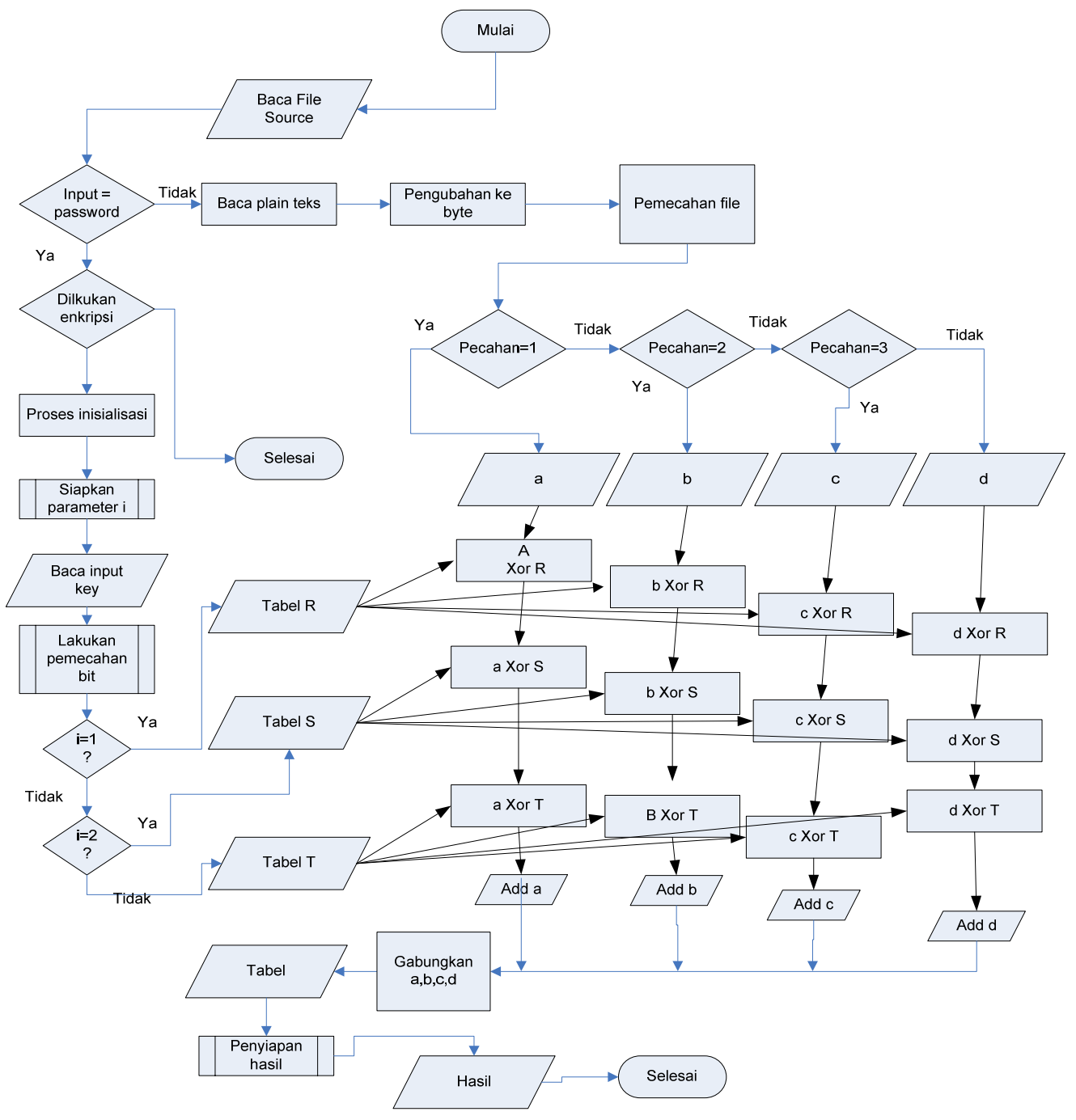

Gambar 2. Diagram Blok proses enkripsi dalam metode SEAL

\section{a. Cara Kerja Enkripsi SEAL}

Untuk proses enkripsi komputer mengambil data dari file ciphertext dan password. Ciphertext dan password diubah ke dalam bentuk byte. Password yang berupa kumpulan byte merupakan input untuk diproses ke dalam algoritma SHA (Secure Hash Algorithm). Hasil dari SHA kemudian dimasukkan kembali ke dalam algoritma SHA yang telah 
dimodifikasi sehingga terbentuk tabel T, S, R. Pada iterasi pertama ciphertext byte dilakukan operasi XOR dengan tabel $\mathrm{S}$, sehingga diperoleh output a,b,c,d. Kemudian masing-masing output tersebut dilakukan proses XOR dengan tabel $\mathrm{T}$, dan yang terakhir dilakukan operasi XOR dengan tabel R. Setelah iterasi terakhir output a,b,c,d ditambahkan menjadi satu dan hasil penambahan tersebut disimpan ke dalam output. Gambar 2 menunjukkan alur kerja proses enkripsi dengan algoritma SEAL.

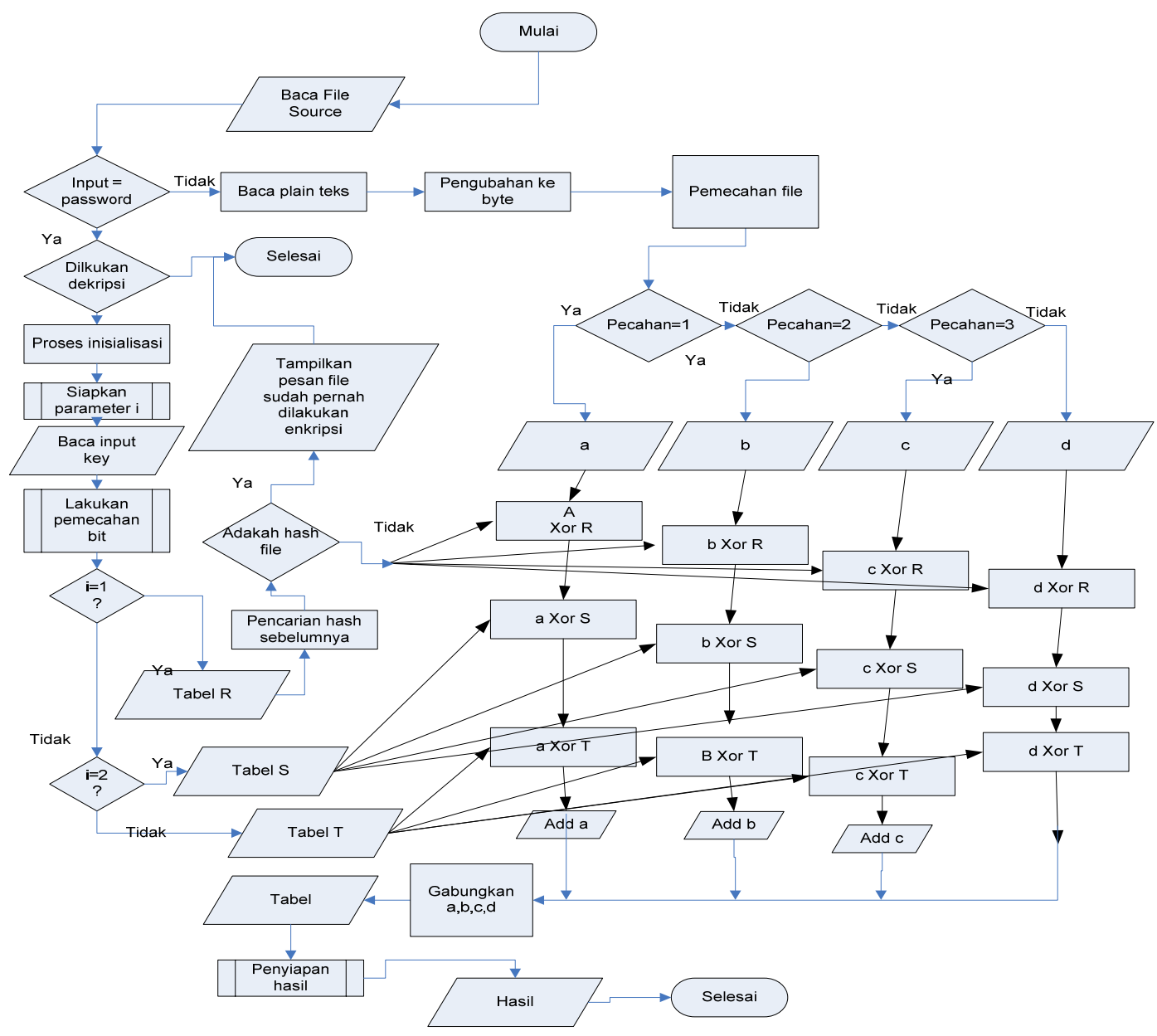

Gambar 3. Diagram Blok Proses dekripsi dalam metode SEAL

\section{b. Cara Kerja Deskripsi SEAL}

Untuk proses deskripsi SEAL pada umunya hampir sama pada proses enkripsi SEAL. Komputer mengambil data dari file ciphertext dan password. Ciphertext dan password diubah ke dalam bentuk byte. Password yang berupa kumpulan byte merupakan input untuk diproses ke dalam algoritma SHA (Secure Hash Algorithm). Hasil dari SHA kemudian dimasukkan kembali ke dalam algoritma SHA yang telah dimodifikasi sehingga terbentuk tabel T, S, R. Pada iterasi pertama ciphertext byte dixorkan dengan tabel S, 
diperoleh a,b,c,d. Kemudian masing-masing output tersebut dixorkan dengan tabel T, dan yang terakhir xor dengan tabel R. Setelah iterasi terakhir output a,b,c,d diadd menjadi satu dan hasil add tersebut disimpan ke dalam output. Gambar 3 menujukkan proses dekompresi algoritma SEAL.

\section{Implementasi dan Pembahasan}

Gambar 4. merupakan tampilan dari form utama dalam program yang dibuat. Yang digunakan untuk proses enkripsi maupun deskripsi .Tampilan utama ini dibuat sesederhana mungkin, namun dapat berfungsi sesuai dengan hal yang diharapkan, dalam tampilan menu utama tersebut terdapat beberapa bagian masukan dan tombol yang digunakan dalam proses enkripsi dan deskripsi.

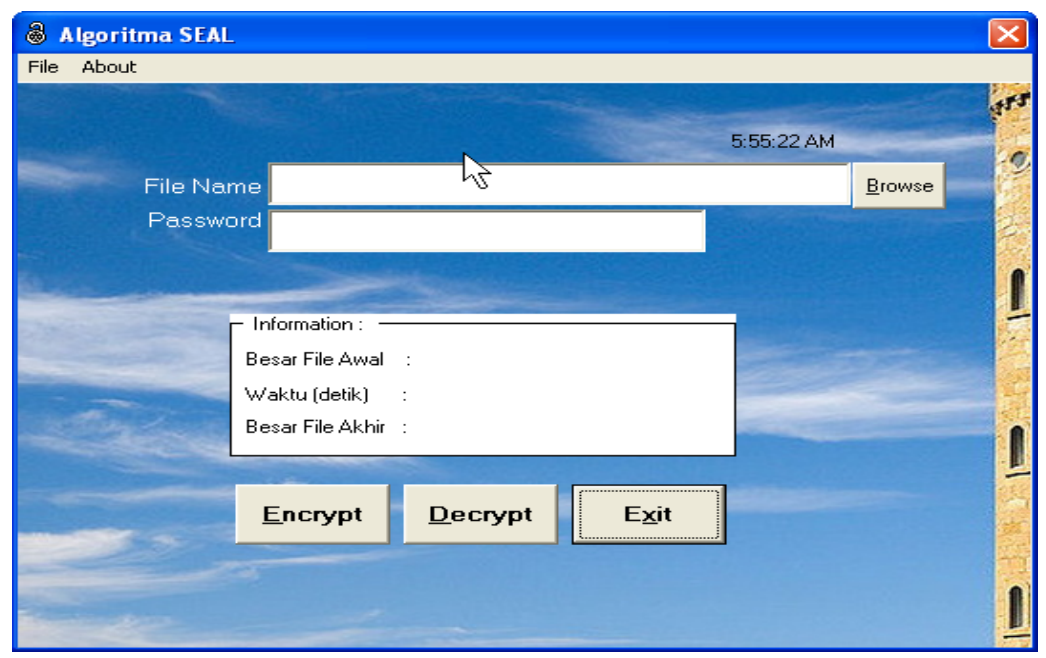

Gambar 4. Tampiln Menu Utama Sistem

Seperti misalnya tempat untuk memasukkan data yang akan di proses baik yang akan dienkripsi maupun dideskripsi, ada juga inputan untuk mencatat password yang digunakan dimana password disini harus sama antara password yang digunakan untuk proses enkripsi dengan password yang digukana untuk proses deskripsi, kemudian ada 2 tombol yang digunakan untuk proses ekripsi dan deskripsi. 


\section{Analisis Hasil}

\subsection{Analisis ukuran file terhadap proses enkripsi / deskripsi}

Tabel 1. Perbandingan besar ukuran file pada proses enkripsi dan dekripsi

\begin{tabular}{|c|c|c|c|c|}
\hline Nama File & $\begin{array}{c}\text { Besar } \\
\text { ukuran file } \\
\text { awal (byte) }\end{array}$ & $\begin{array}{c}\text { Besar } \\
\text { ukuran file } \\
\text { setelah } \\
\text { Enkripsi } \\
\text { (byte) }\end{array}$ & $\begin{array}{c}\text { Selisih } \\
\text { ukuran file } \\
\text { (byte) }\end{array}$ & $\begin{array}{c}\text { Bessar } \\
\text { perubahan } \\
\text { ukuran file(\%) }\end{array}$ \\
\hline komp1.txt & 23 & 88 & 65 & $282.60 \%$ \\
\hline komp9.txt & 1242 & 1304 & 62 & $4.99 \%$ \\
\hline komp11.txt & 2024 & 2088 & 64 & $3.16 \%$ \\
\hline komp13.txt & 3887 & 3952 & 65 & $1.67 \%$ \\
\hline duta1.txt & 5520 & 5584 & 64 & $1.15 \%$ \\
\hline Sepeda.jpg & 988 & 1046 & 58 & $5.87 \%$ \\
\hline Gunung.jpg & 1371 & 1431 & 60 & $4.37 \%$ \\
\hline Baju.jpg & 1677 & 1739 & 62 & $3.69 \%$ \\
\hline Buku_tulis.jpg & 1777 & 1842 & 65 & $3.65 \%$ \\
\hline Palm.jpg & 1803 & 1863 & 60 & $3.32 \%$ \\
\hline $\begin{array}{c}\text { Pengatar } \\
\text { algoritma.doc }\end{array}$ & 1042 & 1104 & 62 & $5.95 \%$ \\
\hline Seal 2.doc & 29696 & 29760 & 64 & $0.21 \%$ \\
\hline $\begin{array}{l}\text { Keamanan } \\
\text { data.doc }\end{array}$ & 47975 & 48037 & 62 & $0.12 \%$ \\
\hline Onno_tcp_ip.doc & 55808 & 55888 & 80 & $0.14 \%$ \\
\hline $\begin{array}{l}\text { Pengantar } \\
\text { enkripsi.doc }\end{array}$ & 69072 & 69156 & 84 & $0.12 \%$ \\
\hline Enkripsi.pdf & 2472 & 2488 & 16 & $0.64 \%$ \\
\hline $\begin{array}{c}\text { Pengatar } \\
\text { multimedia.pdf }\end{array}$ & 3573 & 3592 & 19 & $0.53 \%$ \\
\hline Database.pdf & 6357 & 6376 & 19 & $0.29 \%$ \\
\hline $\begin{array}{l}\text { Keamanan } \\
\text { jaringan.pdf }\end{array}$ & 24061 & 24080 & 19 & $0.07 \%$ \\
\hline Rogaway_seal.pdf & 33388 & 33408 & 20 & $0.05 \%$ \\
\hline
\end{tabular}

Dari tabel 1 di atas dapat dilihat bahwa setiap file mengalami perubahan ukuran besar file setelah dilakukan proses enkripsi.. Hal ini disebabkan oleh penggunaan proses pencarian tabel T, R, dan S, serta proses xor dari tabel T, R, dan S dengan data dalam bagian a,b,c dan pemecahan data file menjadi empat bagian, proses looping membuat perbedaan antar 
kapasitas. Dari setiap file mengalami perubahan besar ukuran file dengan kisaran besar yang hampir sama sehingga tidak ada perlakuan khusus terhadap suatu file. Dengan perubahan ukuran besar file dengan kisaran yang hampir sama menyebabkan semakin besar ukuran file maka semakin kecil porsentase perubahan ukuran besar filenya.

\subsection{Analisis waktu proses terhadap besar ukuran file}

Tabel 2. Perbandingan waktu proses enkripsi dan deskripsi

\begin{tabular}{|c|c|c|c|c|c|}
\hline Nama File & $\begin{array}{c}\text { Besar } \\
\text { ukuran } \\
\text { file } \\
\text { (Byte) }\end{array}$ & $\begin{array}{c}\text { Waktu } \\
\text { proses } \\
\text { Enkripsi } \\
\text { (detik) }\end{array}$ & $\begin{array}{c}\text { Waktu } \\
\text { proses } \\
\text { Deskripsi } \\
\text { (detik) }\end{array}$ & $\begin{array}{l}\text { Selisih } \\
\text { Waktu } \\
\text { (detik) }\end{array}$ & $\begin{array}{l}\text { Bessar } \\
\text { perubahar } \\
\text { waktu(\%) }\end{array}$ \\
\hline komp3.txt & 138 & 0.09838 & 0.30200 & 0.20362 & $206.97 \%$ \\
\hline komp9.txt & 1242 & 0.12988 & 0.27000 & 0.14012 & $107.88 \%$ \\
\hline komp11.txt & 2024 & 0.08313 & 0.25488 & 0.17175 & $206.60 \%$ \\
\hline komp13.txt & 3887 & 0.11425 & 0.30138 & 0.18713 & $163.78 \%$ \\
\hline duta1.txt & 5520 & 0.12963 & 0.31763 & 0.188 & $145.02 \%$ \\
\hline Sepeda.jpg & 988 & 0.036375 & 0.037341 & 0.00096 & $2.65 \%$ \\
\hline Gunung.jpg & 1371 & 0.26365 & 0.27346 & 0.00981 & $3.72 \%$ \\
\hline Baju.jpg & 1677 & 0.26456 & 0.27386 & 0.0093 & $3.51 \%$ \\
\hline$\underset{g}{\text { Buku_tulis.jp }}$ & 1777 & 0.236146 & 0.26358 & 0.02743 & $11.61 \%$ \\
\hline Palm.jpg & 1803 & 0.236569 & 0.261576 & 0.025 & $10.57 \%$ \\
\hline $\begin{array}{c}\text { Pengatar } \\
\text { algoritma.doc }\end{array}$ & 1042 & 0.020937 & 0.022188 & 0.001251 & $5.87 \%$ \\
\hline Seal 2.doc & 29696 & 0.10781 & 0.12055 & 0.01274 & $11.81 \%$ \\
\hline $\begin{array}{c}\text { Keamanan } \\
\text { data.doc }\end{array}$ & 47975 & 0.164875 & 0.186094 & 0.021219 & $12.86 \%$ \\
\hline
\end{tabular}




\begin{tabular}{|c|c|c|c|c|c|}
\hline Nama File & $\begin{array}{c}\text { Besar } \\
\text { ukuran } \\
\text { file } \\
\text { (Byte) }\end{array}$ & $\begin{array}{c}\text { Waktu } \\
\text { proses } \\
\text { Enkripsi } \\
\text { (detik) }\end{array}$ & $\begin{array}{c}\text { Waktu } \\
\text { proses } \\
\text { Deskripsi } \\
\text { (detik) }\end{array}$ & $\begin{array}{c}\text { Selisih } \\
\text { Waktu } \\
\text { (detik) }\end{array}$ & $\begin{array}{c}\text { Bessar } \\
\text { perubahan } \\
\text { waktu(\%) }\end{array}$ \\
\hline $\begin{array}{c}\text { Onno_tcp_ip. } \\
\text { doc }\end{array}$ & 55808 & 0.21406 & 0.24063 & 0.02657 & $12.41 \%$ \\
\hline $\begin{array}{c}\text { Pengantar } \\
\text { enkripsi.doc }\end{array}$ & 69072 & 0.236031 & 0.257562 & 0.021531 & $9.12 \%$ \\
\hline $\begin{array}{c}\text { Enkripsi.pdf } \\
\text { (do) }\end{array}$ & 2472 & 1.019344 & 1.18969 & 0.170346 & $16.71 \%$ \\
\hline $\begin{array}{c}\text { Pengatar } \\
\text { multimedia.p } \\
\text { df }\end{array}$ & 3573 & 1.02125 & 1.131094 & 0.109844 & $10.75 \%$ \\
\hline $\begin{array}{c}\text { Keamanan } \\
\text { jaringan.pdf }\end{array}$ & 24061 & 2.20594 & 2.34312 & 0.13718 & $6.21 \%$ \\
\hline $\begin{array}{c}\text { Database.pdf } \\
\text { Rogaway_se }\end{array}$ & 33388 & 2.033687 & 2.119938 & 0.086251 & $4.24 \%$ \\
\hline
\end{tabular}

Waktu proses enkripsi dan deskripsi file tergantung pada ukuran file yang akan di enkripsi maupun di deskripsi. Dari beberapa percobaan, seperti yang ditunjukkan hasilnya pada Table 2, dapat dilihat waktu yang dibutuhkan setiap file untuk proses enkripsi maupun deskripsi tidak begitu berbeda jauh semakin besar ukuran file yang diproses maka waktu yang dibutuhkan untuk proses enkripsi dan deskripsi juga semakin lama. Hal ini terjadi karena semakin besar ukuran file maka makin lama waktu yang dibutuhkan sistem untuk memecah file maupun untuk melakukan proses perulangan. Semakin lama waktu yang dibutuh pada proses enkripsi maupun deskripsi maka besar perubahan prosentase waktunya semakin kecil dimana kisaran waktu yang dibutuhkan setiap file tidak jauh berbeda sehingga tipe file tidak mempengruhi waktu maupun ukuran file yang dienkripsi maupun yang dideskripsikan. 


\subsection{Analisis pada file dengan ukuran yang hampir sama}

Tabel 3. Perbandingan antara Ukuran file plaintext, gambar, dokumen dan pdf dengan waktu enkripsi

\begin{tabular}{|c|c|c|c|c|c|}
\hline No & Nama File & $\begin{array}{c}\text { Besarnya } \\
\text { file } \\
\text { sebelum } \\
\text { enkripsi }\end{array}$ & $\begin{array}{c}\text { Besar file } \\
\text { setelah } \\
\text { enkripsi }\end{array}$ & $\begin{array}{l}\text { Waktu } \\
\text { Enkripsi }\end{array}$ & $\begin{array}{l}\text { Waktu } \\
\text { Dekripsi }\end{array}$ \\
\hline 1 & enkripsi 1.txt & 140 & 202 & 0.09838 & 0.11048 \\
\hline 2 & analisis 2.txt & 200 & 262 & 0.08271 & 0.09901 \\
\hline 3 & komputer.doc & 147 & 211 & 0.08000 & 0.09420 \\
\hline 4 & algoritma dasar.doc & 195 & 261 & 0.08250 & 0.09480 \\
\hline 5 & robot atas.jpg & 150 & 212 & 0.08105 & 0.09725 \\
\hline 6 & dinding.jpg & 190 & 260 & 0.08263 & 0.09923 \\
\hline 7 & silabus.pdf & 154 & 220 & 0.08300 & 0.09840 \\
\hline 8 & $\begin{array}{l}\text { Perancangan } \\
\text { sistem.pdf }\end{array}$ & 193 & 263 & 0.08245 & 0.09875 \\
\hline
\end{tabular}

Sebenarnya di analisis ini akan dijelaskan untuk perbandingan antar file teks, dokumen, gambar dan pdf dengan kapasitas awal sama, namun karena sangat sulit untuk mencari file dengan kriteria keempat-empatnya sama, maka hanya di berikan contoh untuk perbandingan dengan kapasitas yang tidak jauh berbeda diantara masing-masing file. Dari hasil tabel 3 tersebut terlihat bahwa untuk kapasitas awal dengan akhir berbeda, ini terjadi karena kapasitas yang diinginkan tidak tercapai kesamaannya, sedangkan untuk hasil akhir terdapat sedikit perbedaan, ini sebenaranya hampir sama dengan untuk masing-masing percobaan. Demikian juga untuk waktu yang diperlukan dalam proses enkripsinya. Dengan demikian untuk masingmasing contoh dari percobaan ini, dapat disimpulkan bahwa bentuk file tidak begitu berpengaruh. Hal ini disebabkan proses atau perlakuan yang terjadi pada proses enkripsi maupun dekripsi di masing-masing file adalah sama. 


\subsection{Analisis pada file dengan panjang password berbeda}

Tabel 4. Perbandingan hasil enkripsi dengan panjang password yang berbeda

\begin{tabular}{|c|c|c|c|c|c|}
\hline Nama File & $\begin{array}{c}\text { Besar file } \\
\text { awal } \\
\text { (byte) }\end{array}$ & $\begin{array}{c}\text { Panjng } \\
\text { Password }\end{array}$ & $\begin{array}{c}\text { Besar file } \\
\text { setelah } \\
\text { enkripsi } \\
\text { (byte) }\end{array}$ & $\begin{array}{c}\text { Panjang } \\
\text { Password }\end{array}$ & $\begin{array}{c}\text { Besar file } \\
\text { setelah } \\
\text { enkripsi } \\
\text { (byte) }\end{array}$ \\
\hline komp1.xt & 23 & 1 & 88 & 4 & 88 \\
\hline komp2.txt & 92 & 2 & 152 & 6 & 152 \\
\hline komp3.txt & 138 & 4 & 200 & 8 & 200 \\
\hline komp4.txt & 184 & 6 & 248 & 20 & 248 \\
\hline Clouds.jpg & 1578 & 8 & 1640 & 4 & 1640 \\
\hline Baru.jpg & 145 & 10 & 205 & 6 & 205 \\
\hline Mangga.jpg & 313 & 1 & 377 & 8 & 377 \\
\hline Meja.jpg & 518 & 2 & 581 & 10 & 581 \\
\hline $\begin{array}{l}\text { Pengantar } \\
\text { algoritma.doc }\end{array}$ & 1042 & 4 & 1104 & 4 & 1104 \\
\hline $\begin{array}{l}\text { Sql tingkat } \\
\text { dasar.doc }\end{array}$ & 1226 & 6 & 1286 & 6 & 1286 \\
\hline $\begin{array}{l}\text { Belajar } \\
\text { sql.doc }\end{array}$ & 1637 & 8 & 1701 & 8 & 1701 \\
\hline $\begin{array}{l}\text { Database } \\
\text { 3.doc }\end{array}$ & 1452 & 10 & 1515 & 15 & 1515 \\
\hline $\begin{array}{c}\text { Pengantar } \\
\text { multimedia.pdf }\end{array}$ & 3573 & 1 & 3592 & 4 & 3592 \\
\hline Belajar sql.pdf & 6134 & 2 & 6152 & 8 & 6152 \\
\hline Studi sql.pdf & 8567 & 4 & 8584 & 10 & 8584 \\
\hline Database.pdf & 6357 & 6 & 6376 & 14 & 6376 \\
\hline
\end{tabular}

Dari hasil percobaan pada tabel 5 diatas dapat disimpulkan bahwa panjang password tidak berpengaruh terhadap ukuran besar file maupun waktu dari proses enkripsi maupun proses deskripsi.

\section{Kesimpulan dan Saran}

Dari hasil analisis pada program enkripsi dan dekripsi, dapat ditarik kesimpulan sebagai berikut :

1. Dalam implementasi program dengan menggunakan algoritma SEAL dapat dilakukan 
proses enkripsi dan dekripsi pada file teks, gambar, dokumen word dan pdf .

2. Dalam proses enkripsi maupun deskripsi tipe file tidak begitu mempengaruhi hasil dari proses enkripsi dan deskripsi. Hasil besar ukuran file ataupun hasil kecepatan setelah proses enkripsi dan deskripsi tidak jauh berbeda dan rata rata hampir sama untuk setiap percobaan, hal ini dikarenakan dalam proses enkripsi maupun dekripsi file dibuka secara binary, sehingga tidak memandang bentuk tipe file. Dengan demikian ukuran file mempengaruhi waktu kecepatan secara simetris dalam proses enkripsi dan dekripsi.

3. Terjadinya perubahan besar ukuran file maupun waktu setelah proses enkripsi dikarenakan pada saat proses enkripsi file mengalami beberapa proses yaitu pembentukan hash file, penguraian data, penyisipan data dengan hash file, dan proses pembentukan kembali data file yang di enkripsi.

4. Panjang password pada waktu melakukan proses enkripsi maupun proses deskripsi tidak mempengaruhi besar ukuran file dan waktu yang dibutuhkan file pada waktu proses enkripsi dan deskripsi.

\section{Daftar Pustaka}

[1] Ariyus, D. (2006). Kriptografi keamanan data dan komunikasi. Penerbit Graha IImu Yogyakarta.

[2] Gilbert, H. (2003). Cryptanalisis of the SEAL encryption algorithm. France TelecomCNET.

[3] Menezes, A., J., Oorschot, P. C. V., Vanstone, S. A. (1996). Handbook of applied cryptography. CRC Press.

[4] Ramadhan, A. (2004). Microsoft visual basic 6.0, Elex Media Komputindo, Jakarta.

[5] Rogaway, P., Coppersmith, D. (1997). A software-optimized encryption algorithm. Cambridge Security Workshop, Springer-Verlag.

[6] Schneier, B. (1996). Applied cryptography, $2^{\text {nd }}$ edition. John Wiley \& Sons.

[7] Welschenbach, M. (2001). Cryptography in C and C++. Apress., 